\title{
6
}

\section{Modeling Water Demand Considering Impact of Climate Change - a Toronto Case Study}

\author{
Waiel A. Sadiq and Bryan W. Karney
}

Municipal water demand modeling is a complex process that involves human response to climatic and non-climatic conditions. Forecasting of water demand is indispensable for the daily operation of existing water supply systems and the planning of future systems. The prospect of global climate change added a new dimension to the existing uncertainty associated with the forecasting of municipal demand for water. In this chapter an analysis of Toronto's daily water demand is carried out and a methodology for the forecasting of this demand is provided. A model for the prediction of the daily water demand of the city of Toronto is developed. The model provides a tool to optimize the daily operation of the water supply system with the goal of minimizing energy cost and improving water quality. A second model for the long-term forecasting of Toronto's water demand is also presented. The longterm demand model is used to evaluate the impact of climate change on Toronto's future water demand. The study has shown that a $1^{\circ} \mathrm{C}$ increase in summer maximum daily temperature would result in a $2 \%$ increase in average summer demand and $1.8 \%$ increase in peak day demand. Toronto's peak day demand of year 2000 would increase by $23 \%$ as a result of a $15 \%$ increase in population coupled with having a summer in which the maximum daily temperature increase by $5^{\circ} \mathrm{C}$ and the rainfall decrease by $10 \%$. Planners and engineers need to consider climate change scenarios in the planning strategy of future water supply systems and delivering projects.

\subsection{Introduction}

An important goal of any water supply authority is to achieve a balance between supply and demand at a level that is acceptable to consumers. The

Sadiq, W.A. and B. Karney. 2005. "Modeling Water Demand Considering Impact of Climate Change - a Toronto Case Study." Journal of Water Management Modeling R223-06. doi: 10.14796/JWMM.R223-06.

(C) CHI 2005 www.chijournal.org ISSN: 2292-6062 (Formerly in Effective Modeling of Urban Water Systems. ISBN: 0-9736716-0-2) 
level of consumer satisfaction is measured for four distinct features: quality, quantity, pressure, and price of water. For the water authority, the goal is to satisfy the consumer need at minimum cost. To accomplish this objective, management of available resources becomes crucial, while planning as a tool to prepare for the coming future becomes imperative. For successful municipal planning and management, the need arises to determine the demand for water, in the sense of quantity and time. Thus the issue of demand forecasting comes into action.

Water resources management has been undergoing non-stop changes due to population growth, economic development, technological revolution, and legislative changes. These changes will continue in the future. Meanwhile, another aspect that may influence daily activities has emerged. Climate is changing continuously and at an increasing pace. The issue of climate change has added a new dimension to the ongoing dynamics of water supply and demand planning. Increase in maximum daily temperature and drier summer period increases the demand for water. On the other hand, climate change may cause cultural changes in water use that will trigger lower water demand due to increase in water conservation measures. To prepare for an uncertain future there is a need to understand the past, evaluate the relationship between the factors that influence the demand, predict possible forthcoming scenarios, and plan for their arrival.

The specific study area for this chapter is the City of Toronto. The first objective of the current work is to study and evaluate daily water demand in view of climatic conditions. The aim is to investigate the presence of anomalies in daily demands, explain such anomalies, and to investigate the correlation between water demand and climatic variables.

The second objective is to develop a water demand forecasting tool. Depending on the end use, two models are explored in the study. The first is for the prediction of the next day water demand. The objective of the model is to allow system operators to estimate beforehand the daily demand in order to make the necessary adjustment in the system operation to meet such demand at minimum cost. The second model is for the forecasting of the long-term water demand of the city. In other words, trying to answer the question "What will be Toronto's water demands, average as well as peak, several years from now?"

The third objective is to study the impact of possible climate change on future water demands in Toronto. The long-term water demand model is adopted to conduct a sensitivity analysis for the impact of climatic and nonclimatic factors on future demands. Sensitivity analysis allows conclusions to 
be made regarding the importance of each factor separately with respect to the water demand. The consequence of combined changes in these factors is studied to determine the impact of such combination on water demand.

The link between climate and water demand is usually represented in water demand models by the historical relationship between water demand, temperature, and precipitation (Miaou, 1990a). Climate change complicates the interpretation of this link. Key parameters that define the distributions of variables, such as temperature, change over the forecasting period. Moreover, small changes in average parameter values may have a dramatic effect on the intensity and duration of extreme events (Colombo et al., 1999, Wigley, 1988). Prolonged periods of warm weather coupled with diminished precipitation could lead to progressively higher daily water demand as the event persists. The major source of increased demand would be the seasonal application of water to lawns and vegetation.

Assessment of possible climate change and its impact on water demand includes understanding the dynamics of water demand, calculating the sensitivity of water demand to climatic variability, and calculating the probability of future water demands based on different climate scenarios taking into consideration uncertainty in the underlying assumptions. Cohen (1987) estimated that a $1{ }^{\circ} \mathrm{C}$ warming would increase summer municipal water demand in the Great Lakes Region by $1.3 \%$. Cohen also indicated that this projection is probably conservative as continuous extreme summer hot waves would notably increase the demand for water.

In a study on the impact of climate change on water demand in the United Kingdom, Herrington (1996) concluded that, in the absence of climate change, water demand is expected to increase by $12 \%$ to $38 \%$ in year 2021 compared to year 1991 demand. The effect of climate change is expected to add another $4 \%$ to that increase. Herrington suggested that without climate change, the seven-day domestic peak demand will increase between $44 \%$ and $50 \%$ in year 2021 from that of year 1991. Imposing climate change will transform such increase to be between $59 \%$ and $69 \%$.

\subsection{Methodology}

Water demand is a complex process that involves response to several influencing climatic and non-climatic factors. During the summer season the demand for water is partially a response to the need for water for plants to grow, and partially a psychological response to the appearance of plants 
showing signs of distress due to high temperature even though sufficient soil moisture is available for growth. The use of physical variables and equations to describe the collective action of people only approximates an underlying complex process. In fact, climatic variables used to describe water demand should be considered to be only indicator variables (Maidment et al., 1985).

Our research started by identifying variables that influence and explain variation in daily water demand. Several climatic and non-climatic variables have been examined:

$T i$

$T i-1$

$T i-2$

$D T i$

$P i$

$R i$

Di-1

NDSR $i$

$P O P$ maximum temperature at day $i,\left({ }^{\circ} \mathrm{C}\right)$, maximum temperature at day $i-1,\left({ }^{\circ} \mathrm{C}\right)$, maximum temperature at day $i-2,\left({ }^{\circ} \mathrm{C}\right)$, type of day $i$, weekend/holiday or weekday, rainfall amount occurring at day $i,(\mathrm{~mm})$, presence of rainfall at day $I, R=0,1$ for no rain or rain, recorded water demand at day $i-1,(\mathrm{ML} / \mathrm{d})$,

For precipitation $\left(P_{i}\right)$ only rainfall events with depth of $0.2 \mathrm{~mm}$ or larger are evaluated. $R_{i}$ is a variable that describes the response to probable occurrence of a rainfall event in the day during the summer period. During dry days the tendency is to water the gardens increasing the demand, however, during wet days gardens are not watered and the demand decreases. Statistical analysis of the demand data has shown that the occurrence of rainfall on the day influences water consumption more than the amount of rainfall. The effect of having dry periods on daily water demand is evaluated using the variable NDSR.

The analysis of the relationship between water demand and maximum daily temperature has shown that an important correlation exists between the demand for water and the maximum temperature. Figure 6.1 shows the relationship between daily maximum temperature and water demand. During the summer period average water demand is found to increase proportionally with the number of days in which the maximum temperature exceeds $15^{\circ} \mathrm{C}$ as shown in Figure 6.2. Investigating the relationship between rainfall amount and daily water demand does not indicate a specific relationship between the two. However, it has been observed that the highest demand occurs during dry periods as shown in Figure 6.3. On the other hand, Figure 6.4 indicates that the demand for water increase as the number of days with no rainfall increases the demand for water increase. 
To capture the impact of maximum temperature on daily water demand in the current work, a threshold temperature of $15^{\circ} \mathrm{C}$ is selected to separate demands sensitive to temperature from demands insensitive to temperature. This threshold temperature is used to develop two different equations for the estimation of demands depending on the daily maximum temperature.

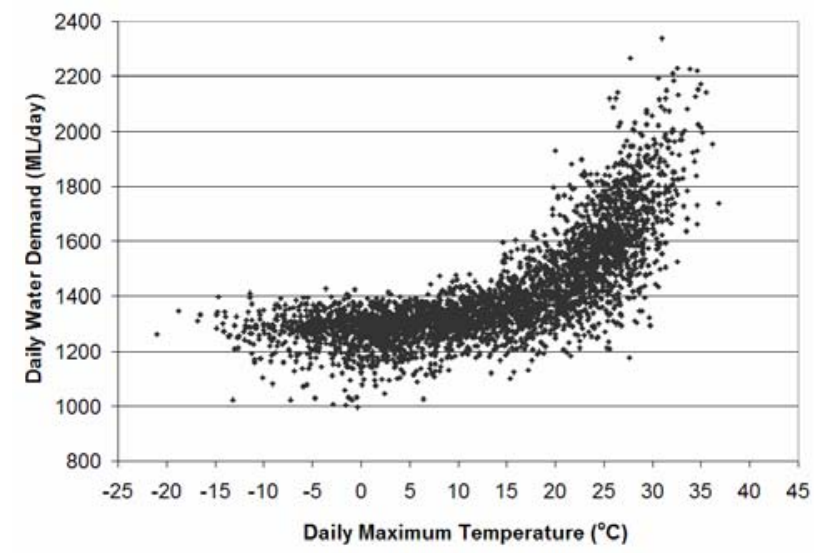

Figure 6.1 Relationship between daily water demand and maximum temperature.

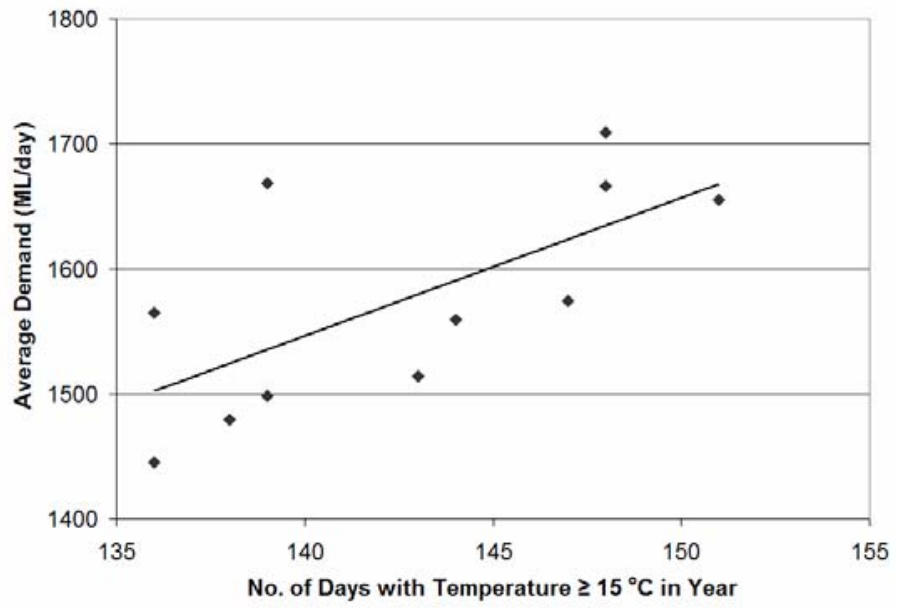

Figure 6.2 Relationship between average water demand and number of days with maximum temperature $\geq 15^{\circ} \mathrm{C}$. 


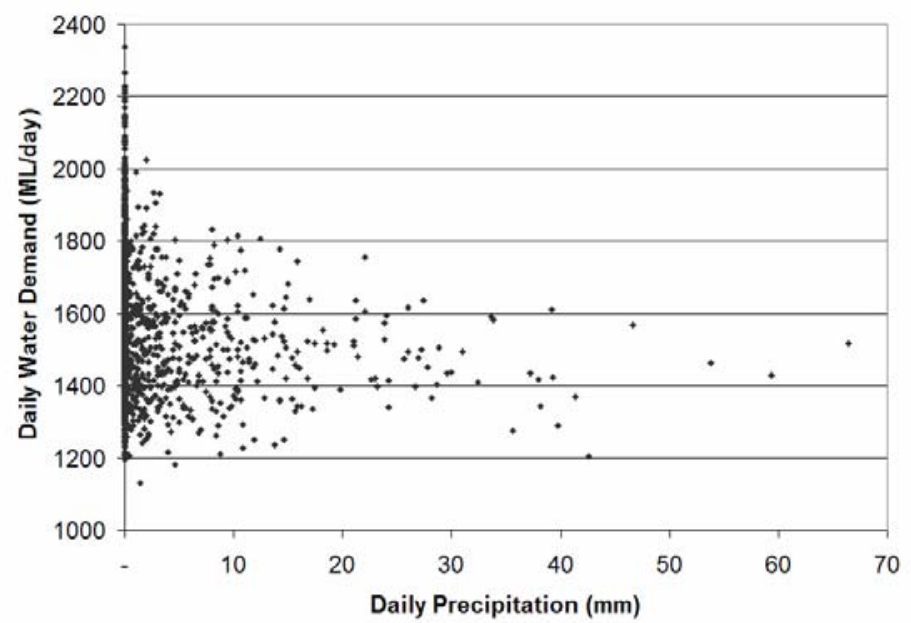

Figure 6.3 Relationship between daily water demand and precipitation.

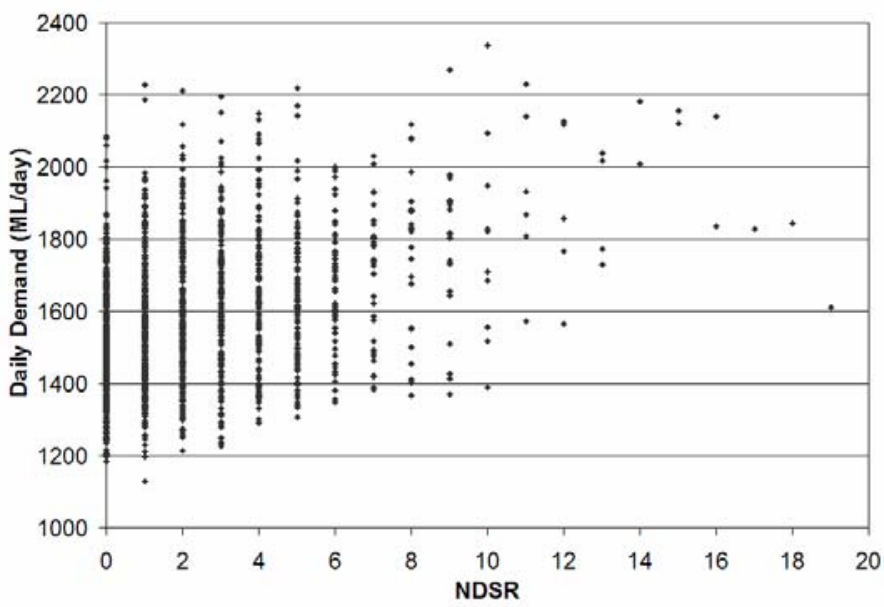

Figure 6.4 - Relationship between daily water demand and number of days with no rainfall (NDSR).

The model formulation is based on a stepwise linear regression method that is adopted by Miaou (1990b). The procedure uses the sequential input variable selection concept of stepwise regression and the "three-step" model building 
strategy formulated by Box and Jenkins (1976). Zhou et al. (2000, 2001) used this method to develop model for the daily water demand forecasting of Melbourne, Australia.

Maximum daily temperature is selected to be the first variable to enter in the stepwise regression procedure for the formulation of the demand model. Daily demand at temperature greater than or equal to $15^{\circ} \mathrm{C}$ is regressed first to obtain the first step regression equation in which only maximum temperature is the explanatory variable. In the second step, the regression residuals are regressed against a second variable. In this step, a number of variables are used one variable at a time. The aim is to detect which variable best explains the residuals from the first regression equation. This procedure is repeated until no significant correlation can further be observed between the last regression residuals and the remaining variables.

Two approaches are considered with respect to the influence of population on demand. In the first, population is assumed to have no significant impact and the analysis proceeds starting from the threshold temperature. In the second, population impacts water demand. In this case the demand is taken to consist of two components, base demand that is climate insensitive and seasonal demand that correlates with climatic factors. The stepwise regression process is applied to the seasonal demand as described above while the base demand is regressed against population only.

Water demand and climatic data from 1991 up to 2000 have been used for model formulation and development. Year 2001 water demands are used for model testing and validation. Two ways are used to compare the agreement between estimated and measured water demands: graphical plots, and statistical parameters (mean and standard deviation). Two dimensionless coefficients are used in assessing model adequacy: the coefficient of multiple determinations $\left(R^{2}\right)$, and the mean absolute error $(M A E)$. Model standard error $(S E)$ is also used to measure the relative errors in model estimations. The efficiency of the model is judged based on the values of $R^{2}, M A E$, and $S E$. Values of $R^{2}$ close to unity indicate that the model can reproduce satisfactorily the recorded demand. MAE determines the difference between predicted and measured demands.

\subsection{Daily Water Demand Model}

The daily water demand model is used to predict the water demand for the daily operation of the water supply system. The stepwise regression procedure 
is used to develop the daily operation demand model. The final form of the model for the estimation of the water demand at day $i\left(D_{i}\right)$ is:

For temperature $\geq 15^{\circ} \mathrm{C}$ :

$\mathrm{D}_{\mathrm{i}}=372+29.2 * \mathrm{~T}_{\mathrm{i}}+0.4 * \mathrm{D}_{\mathrm{i}-1}-91.1 * \mathrm{DT}_{\mathrm{i}}-5.4 * \mathrm{~T}_{\mathrm{i}-1}-59.4 * \mathrm{R}_{\mathrm{i}}+5.4 * \mathrm{NDSR}_{\mathrm{i}}$

For temperature $>15^{\circ} \mathrm{C}$ :

$\mathrm{D}_{\mathrm{i}}=365+0.7 * \mathrm{D}_{\mathrm{i}-1}-42.2 * \mathrm{DT}_{\mathrm{i}}$

Analysis of the model results has shown that the model did not accurately reflect water demands in the months of April, October, and November. During these months, the presence of odd days with high temperature caused the model to overestimate the demand. Gardening season usually starts from the second week of May. Prior to that period, the impact of isolated high temperature events on water demand is not significant. Similarly, temperature will not affect the demand for water in October and November (fall season).

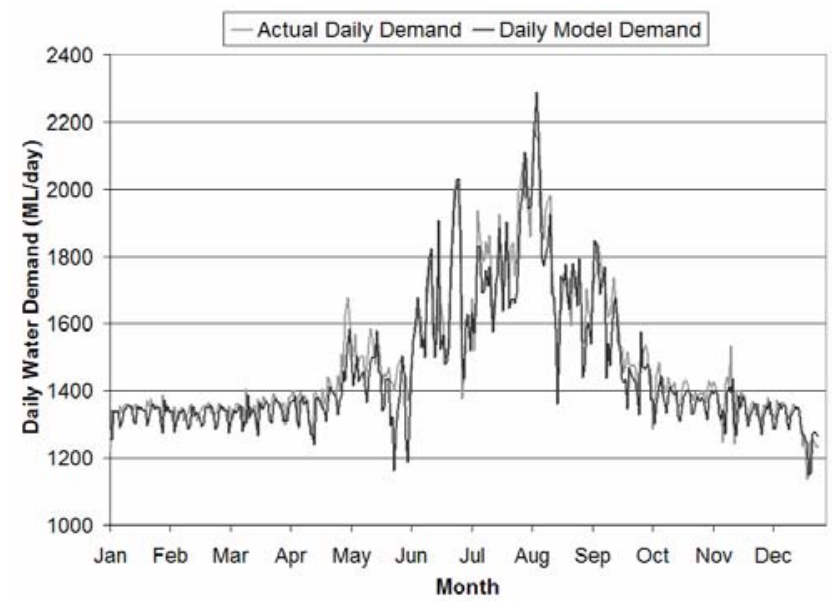

Figure 6.5 Year 2001 vs. Calculated Water Demands.

To mirror the above, consideration is given to the influence of the month in the application of the model. From mid of May to end of September the choice to use either Equation 6.1 or Equation 6.2 to estimate daily water demand depends on the maximum temperature $T_{i}$. For the period from October to mid of May Equation 6.2 is used to estimate the demand regardless 
of the maximum temperature. The overall simulation ability of the daily model has improved when the influence of both the month of the year and the maximum temperature on the demand for water has been considered. The model has an overall $R^{2}$ of $0.896, S E$ of $10.73 \mathrm{ML} / \mathrm{d}$, and $M A E$ of $3.3 \%$.

The calculated demand is compared to recorded demand to check for any significant differences between the two. Figure 6.5 represents year 2001 daily water demands and the model calculated demands. Over the whole year of 2001 , the model $R^{2}$ is 0.888 , the $S E$ is $10.32 \mathrm{ML} / \mathrm{d}$, and the MAE is $3.2 \%$. For the summer period of year 2001 (May to September), the model gave $R^{2}$ of $0.885, S E$ of $16.77 \mathrm{ML} / \mathrm{d}$, and $M A E$ of $4.3 \%$. The calculated peak day demand is found to be $4.9 \%$ higher than peak demand. For the summer months, the calculated monthly average is lower than the monthly average with an error ranging from $-0.8 \%$ to $-4.7 \%$. Maximum error in the calculated daily water demands varies from $-16.9 \%$ in May to $+8.8 \%$ in August.

\subsection{Long-term Water Demand Model}

Evaluation of the impact of climate change is carried out in two steps. Firstly, a long-term demand forecasting model is developed. In the second step the developed long-term forecasting model is used as a mechanism to test the sensitivity of the daily water demand to change in variables associated with climate change such as temperature, and precipitation. The results of the sensitivity analysis provide a tool to draw conclusions about what impact climate change may have on the ability of the water distribution system to meet future water demands and to mitigate the risks associated with ignoring such a change.

In the long-term forecasting model, the impact of population change on water demands is taken into consideration during model development. Total daily demand is taken to consist of "Base Demand" and "Seasonal Demand."

The stepwise regression procedures followed in developing the daily water demand model are used to develop the equations for the long-term demand model. The final form of the model is given as:

For temperature $\geq 15^{\circ} \mathrm{C}$ :

$D_{i}=-796+0.6 * P O P+29 * T_{\mathrm{i}}-106.3 * D T_{i}+4.3 * T_{i-1}+2.4 * T_{i-2}-60.5 * R_{i}+13.5 * N D S R_{i}$

For temperature $>15^{\circ} \mathrm{C}$ :

$$
D_{i}=-284+0.6^{*} P O P
$$


The long-term demand model is tested using an independent data set from January 2001 to December 2001. The calculated water demands are compared to the recorded demands. The calculated peak demand is found to be $8 \%$ higher than peak day demand. For the summer period, the calculated monthly average is higher than the monthly average for most of the months with an error ranging from $-7.6 \%$ to $+1.4 \%$. Maximum errors in the calculated daily demand vary from $-20.8 \%$ in the month of May to $+13.1 \%$ in the month of July.

\subsection{Impact of Climate Change in Toronto}

Different scenarios are considered for the variation in each individual variable that would influence the water demand during climate change. A combination of changes in two or three of these variables has also been evaluated. In the analysis, the summer period has been largely accentuated. Summer daily water demands are highly correlated with climatic conditions.

Year 2000 has been taken as the base year for the purpose of performing the sensitivity analysis. The average summer temperature for year 2000 is $22.9^{\circ} \mathrm{C}$ with 62 days in which the daily maximum temperature exceeded $25^{\circ} \mathrm{C}$. Average summer precipitation for year 2000 is $2.8 \mathrm{~mm} / \mathrm{d}$ with 62 days in which the rainfall intensity exceeded $0.2 \mathrm{~mm} / \mathrm{d}$. For year 2000 , the estimated average summer demand is $1566 \mathrm{ML} / \mathrm{d}(0.4 \%$ higher than average $)$ and the estimated peak day demand is $1952 \mathrm{ML} / \mathrm{d}(2.7 \%$ higher than peak).

Three scenarios of population change are considered; a 5\%, 10\%, and 15\% increase from year 2000 population. The effect of population change is found to be more substantial on summer average demand than it is on summer peak day demand. A $5 \%$ increase in population is found to cause a $5.1 \%$ increase in average summer demand and a $4 \%$ increase in peak day demand.

In the analysis of the impact of temperature change, summer maximum daily temperature has been taken to increase by $1^{\circ} \mathrm{C}, 2^{\circ} \mathrm{C}, 3^{\circ} \mathrm{C}$, and $5^{\circ} \mathrm{C}$. The increase in maximum temperature is applied in the period from May to September of the year. An increase in summer maximum temperature by $1^{\circ} \mathrm{C}$ would result in $2 \%$ increase in summer average demand and a $1.8 \%$ increase in peak day demand. Possible increase in maximum daily temperature by $2^{\circ} \mathrm{C}$ to $5^{\circ} \mathrm{C}$ would cause an increase in peak day demand by $3.6 \%$ to $9.1 \%$ from year 2000 peak demand. On the monthly level the impact of temperature increase on monthly water demand range from $+1.2 \%$ to $+2.3 \%$ per $1{ }^{\circ} \mathrm{C}$. 
The study of the impact of precipitation change on water demand is performed assuming that drier summer will take place. Two precipitation scenarios are considered in the sensitivity analysis. In precipitation scenario 1 the rainfall amount in the summer would decrease by $10 \%$ along with one-day increase in the number of days since a significant rainfall event occurs. In precipitation scenario 2 the rainfall amount would decrease by $30 \%$ while the number of days since a significant rainfall event would increase by three consecutive days. Precipitation scenario 1 causes an increase in the average water demand by $0.6 \%$, while scenario 2 increases the average demand by $0.8 \%$. The impact of having a drier summer on the peak day demand would be doubled from $0.7 \%$ for the first scenario to $1.4 \%$ for the second. Reduced rainfall would influence peak day demand more than it influences average demand.

Over a long period, several factors that affect water demand may vary simultaneously. At the same time during which maximum daily temperature increases, population may also be increasing, and precipitation may be decreasing (the worst case scenario). The effect of a combination of population, temperature, and precipitation changes is evaluated in order to get a comprehensive representation of the long-term impact of climate change. Sensitivity analysis of four combined scenarios is performed. These scenarios are:

1 Combined Scenario 1: Population increase by $15 \%$ plus an increase in summer maximum daily temperature of $2^{\circ} \mathrm{C}$.

2. Combined Scenario 2: Population increase by $15 \%$ plus an increase in summer maximum daily temperature of $5^{\circ} \mathrm{C}$.

3. Combined Scenario 3: Population increase by $15 \%$ plus an increase in summer maximum daily temperature of $2^{\circ} \mathrm{C}$ and a $10 \%$ decrease in daily precipitation.

4. Combined Scenario 4: Population increase by $15 \%$ plus an increase in summer maximum daily temperature of $5^{\circ} \mathrm{C}$ and a $10 \%$ decrease in daily precipitation.

Combined scenario 1 would cause $19 \%$ increase in summer average demand and $16 \%$ increase in peak day demand. In combined scenario 2 the average summer demand would increase by $25 \%$ and peak day demand by $21 \%$. Combined scenario 4 would result in an increase of $26 \%$ in the average summer demand and $23 \%$ in the peak day demand. The analysis shows that the combined effect of population and temperature increase coupled with reduction in precipitation would cause significant increase in both summer average demand as well as peak day demand. 


\subsection{Conclusions}

The study demonstrated that there is a significant correlation between climate and water demand in Toronto. High positive correlation exists between summer daily water demand and daily maximum temperature. Persistent hot weather causes the City water demand to increase especially in the absence of rain. In contrast, negative correlation is observed between daily demand and the presence of rainfall in the day as well as the intensity of the rainfall event. The occurrence of dry summer weather intensifies the need for water, and the longer the dry spell continues the higher its impact would be. Positive correlation is also found between demand and population. Daily water demand is further influenced by type of day.

A cost-effective operation of the water supply system in Toronto requires that the operators of the system be able to estimate the daily water need in advance. Next day water demand would be pumped and stored during off peak hours for use during peak hours, reducing energy cost. Depending on the daily temperature, two equations are formulated to predict next day water demand. The adopted daily demand model depends climatically on the maximum temperature, previous day maximum temperature, the presence of rainfall event, and the number of days since a significant rainfall event has occurred. Non-climatic factors in the model include the previous day demand and the type of day (weekday or weekend).

Maximum daily temperature has been found to explain more than $50 \%$ of the variability in the daily water demand. The presence of rainfall has been shown to be more important than rainfall amount. Reaction to rainfall is sometimes more of a psychological nature than a physical one. For the daily water demand prediction, population variability does not have a major influence. The slow and gradual influence of population change on daily demand is captured in the recorded previous day demand. The developed model has been used to forecast daily water demands for Toronto in year 2001. The overall $R^{2}$ of the model for year 2001 forecast is 0.885 and the mean absolute error is $3.2 \%$. The model reflected satisfactorily the daily variation in water demands.

Long-term planning of the water supply system requires knowledge about the city water demand several years in advance. Depending on the maximum temperature, two equations are used to predict future long-term water demands. Below the threshold temperature, water demand is taken to be insensitive to climatic conditions and is a function of population only. Above the threshold temperature, the adopted long-term demand model depend 
climatically on the maximum daily temperature, previous two days maximum temperature, the period since a rainfall event of at least $0.2 \mathrm{~mm} / \mathrm{d}$ occurred, and the presence of rain in the day. Population and type of day are the nonclimatic factors included in the long-term model. For the long-term demand, population plays a major role in the prediction process.

The developed long-term demand model is used to study the impact of possible climate change on Toronto's water demand. Sensitivity analysis is conducted to evaluate the impact of several climate change scenarios on the demand for water. Population influence is found to be more significant for the summer average demands than it is for the peak day demands. Summer average demand would increase by more than $5.1 \%$ for every $5 \%$ increase in population. With respect to temperature change, it is found that every $1{ }^{\circ} \mathrm{C}$ increase in Toronto maximum daily summer temperature would cause a $2.0 \%$ increase in the summer average demand and $1.8 \%$ increase in the peak day demand. Reduction in summer precipitation coupled with longer dry spells causes a higher rate of increase in peak day demands than in average demands.

A combination of population, temperature, and precipitation impact on long-term water demand has also been studied. The analysis of the combined changes indicates that such impact cannot be neglected. A combination of population, maximum temperature, and precipitation change may cause up to $26 \%$ increase in the summer average daily demands and up to $23 \%$ increase in the peak demands from year 2000 levels.

A possible increase in Toronto water demand due to climatic variability should not be disregarded. The prospect of having hot dry summer season is highly probable and ought to be considered in the City plans. Ignoring climate change would make Toronto vulnerable in the face of uncertain future. Infrastructure alternatives should be evaluated with and without potential climate change impact.

The results of this research could have several spin-off effects on the future development of Toronto. Adaptive measures are needed to alleviate the consequence of a forthcoming climate change. The City planning and management policy should take account of an uncertain climate so that Toronto would be ready to face a future that is not far away.

\section{Acknowledgments}

The contribution of David Etkin from Environment Canada and Jeff Buchyns from the Works and Emergency Services, City of Toronto, in carrying out the 
research is gratefully acknowledged. The daily water demand data are provided by the Works and Emergency services of the City of Toronto. Daily maximum temperature and rainfall data were obtained from Environment Canada.

\section{References}

Box, G. E. P., and Jenkins, G. M. (1976). "Time series analysis: Forecasting and control." Holden-Day, San Francisco, California, 575 pp.

Cohen, S. J. (1985). "Effects of climatic variations on water withdrawals in metropolitan Toronto." Canadian Geographer, 29(2), 113-122.

Cohen, S. J. (1987). "Projected increases in municipal water use in the Great Lakes due to CO2-induced climatic change.” Water Resources Bulletin, 23(1), 91-101.

Colombo, A. F, Etkin, D., and Karney, B. W. (1999). "Climate variability and the frequency of extreme temperature events for nine sites across Canada: Implications for power usage." Journal of Climate, 12, 2490-2502.

Herrington, P. (1996). "Climate change and the demand for water." London: Department of the Environment, HMSO.

Maidment, D. R., Miaou, S. P., and Crawford, M. M. (1985). "Transfer function of daily urban water use." Water Resources Research, 21(4), 425-432.

Miaou, S. P. (1990a). "A class of time series urban water demand models with nonlinear climatic effects." Water Resources Research, 26(2), 169-178

Miaou, S. P. (1990b). "A stepwise time series regression procedure for water demand model identification." Water Resources Research, 26(9), 1887-1897

Wigley, T. M. L. (1988). "The effect of changing climate on the frequency of absolute extreme events." Climate Monitor, 17(2), 44-55.

Zhou, S. L., McMahon, T. A., Walton, A., and Lewis, J. (2000). "Forecasting daily urban water demand: A case study of Melbourne." Journal of Hydrology, 236, 153-164.

Zhou, S. L., McMahon, T. A., and Wang, Q. J. (2001). "Frequency analysis of water consumption for metropolitan area of Melbourne." Journal of Hydrology, 247, 72-84.

Zhou, S. L., McMahon, T. A., Walton, A., and Lewis, J. (2002). "Forecasting operational demand for an urban water supply zone." Journal of Hydrology, 259, 189-202. 